\title{
Antioxidant vitamins in the diet: relationships with other personal characteristics in Finland
}

\author{
Ritva Järvinen, Paul Knekt, Ritva Seppänen, Antti Reunanen, Markku Heliövaara, \\ Jouni Maatela, Arpo Aromaa
}

\begin{abstract}
Study objective - The study aimed to reveal associations between dietary antioxidant vitamins and other personal characteristics.

Design - Population based, cross sectional survey.

Setting - Twenty seven rural, industrial, and semiurban communities in six different regions of Finland.

Participants - Subjects included 5304 men and 4750 women aged 15 years or older, who were interviewed about their dietary habits at the baseline study of the Finnish Mobile Clinic Health Examination Survey, 1967-72.

Main results - Intakes of carotenoids and vitamins $A, E$, and $C$ were estimated from dietary history interviews covering the subjects' food consumption in the preceding year. In older age groups intakes of all the vitamins studied were low. Occupation had a profound effect on dietary antioxidant vitamins: intakes were highest in white collar workers and lowest in farmers; those classified as service workers, industrial workers, or housewives came in between. Current smoking was inversely associated with dietary carotenoids and vitamin $\mathrm{C}$, especially in men. The vitamin intakes of ex-smokers were equal to or even slightly higher than those of never smokers. Married men had higher intakes of carotenoids and vitamin $C$ than men living alone. Body mass index was not an important determinant of the intake of antioxidant vitamins.
\end{abstract}

Conclusions - The associations of dietary antioxidant vitamins with sociodemographic characteristics and smoking were strong enough to exert a confounding or modifying effect in studies on diet and diseases.

( $\mathcal{F}$ Epidemiol Community Health 1994;48:549-554)

R Järvinen

Research and

Development Unit,

The Social Insurance

Institution, Helsinki,

Finland

P Knekt

$R$ Seppänen

A Reunanen

M Heliövaara

J Maatela

A Aromaa

Correspondence to:

Ms R Järvinen.

Accepted for publication

March 1994

Much interest has recently been focussed on antioxidant agents in the diet. Because they can prevent or reduce oxidative changes in tissues, these agents may combat the initiation or progression of degenerative diseases. Dietary nutrients thought to have very strong antioxidant effects are carotenoids and vitamins $C$ and E. ${ }^{1}$ There is both experimental and epidemiological evidence supporting a beneficial illnesses such as cancer and cardiovascular diseases. ${ }^{1-3}$ These diseases are, however, multifactorial in their origins, and are known to be associated with several other personal characteristics, such as age, sex, smoking, social standing, and obesity. Because of the suggested inter-relations between diet and other personal characteristics, ${ }^{4-12}$ their relative importance in disease outcome is complicated. Better knowledge of these relationships would assist in establishing their roles as risk factors of chronic diseases. In this study, the associations between selected demographic and health behaviour related variables and the dietary intake of carotenoids and vitamins $\mathrm{A}, \mathrm{C}$, and $\mathrm{E}$ were evaluated among the Finnish adults who participated in the Finnish Mobile Clinic Health Examination Survey.

\section{Methods}

A large scale health examination survey was carried out in Finland during 1966-72. ${ }^{13}$ The target population of the study comprised people aged 15 years or older living in 27 rural, industrial, or semiurban communities in six different regions of the country. Collection of dietary data was included in the study schedule in 1967. Approximately one in five of those who participated in the health examination were interviewed about their dietary habits. Altogether, 10054 dietary history interviews were conducted.

A modified interview method ${ }^{14}{ }^{15}$ was used to collect information on the subjects' diet during the previous year. Intakes of different food items and mixed food dishes were determined in interviews guided by a preformed questionnaire. Intakes of foods with strong seasonal fluctuation were determined separately for different seasons. Food amounts were given per day, week, month, or year according to the choice of the respondent. Foods eaten at breakfast were reported separately. Artificial food models or samples of real food were used to assist the estimation of food amounts. The time taken for the interview averaged 30 to 40 minutes. role for these vitamins in preventing chronic

More than 500 different individual foods or dishes containing a variety of ingredients were recorded in the interviews. Daily intakes of different food items and nutrients were calculated using food composition tables, which included recipes for mixed food dishes and gave nutrient contents for separate food items. Food values for different tocopherols and tocotrienols, ${ }^{16}$ and for specific carotenoids and retinoids, ${ }^{17}$ were based on values analysed in 
Table 1 Means and centile distributions for intakes of dietary antioxidant vitamins, related nutrients, and dietary energy in men and women

\begin{tabular}{|c|c|c|c|c|c|c|c|c|c|c|}
\hline \multirow[t]{3}{*}{ Daily intake } & \multicolumn{5}{|c|}{$\operatorname{Men}(n=5304)$} & \multicolumn{5}{|c|}{ Women $(n=4750)$} \\
\hline & \multirow[t]{2}{*}{ Mean } & \multirow[t]{2}{*}{$(S D)$} & \multicolumn{3}{|c|}{ Centiles } & \multirow[t]{2}{*}{ Mean } & \multirow[t]{2}{*}{$(S D)$} & \multicolumn{3}{|c|}{ Centiles } \\
\hline & & & $10 t h$ & 50 th & $90 t h$ & & & $\overline{10 t h}$ & $50 t h$ & $90 t h$ \\
\hline Vitamin A (REq, $\mathrm{mg})$ & 1.68 & $(0.97)$ & $0 \cdot 81$ & 1.45 & $2 \cdot 78$ & 1.57 & $(0.98)$ & 0.67 & 1.33 & $2 \cdot 75$ \\
\hline Retinoids (REq, mg) & $1 \cdot 38$ & $(0 \cdot 86)$ & 0.65 & $1 \cdot 19$ & $2 \cdot 30$ & $1 \cdot 16$ & $(0.78)$ & 0.49 & 0.98 & 2.04 \\
\hline Carotenoids (mg)* & $1 \cdot 76$ & $(1 \cdot 84)$ & 0.54 & $1 \cdot 15$ & 3.65 & $2 \cdot 46$ & $(2 \cdot 81)$ & 0.53 & 1.57 & $5 \cdot 24$ \\
\hline$\beta$-carotene (mg) & $1 \cdot 70$ & $(1 \cdot 77)$ & 0.53 & $1 \cdot 11$ & 3.52 & $2 \cdot 37$ & $(2 \cdot 71)$ & 0.51 & 1.50 & $5 \cdot 04$ \\
\hline Vitamin E (mg) & 8.51 & $(3 \cdot 68)$ & 5.00 & $7 \cdot 75$ & 12.85 & $6 \cdot 56$ & $(2 \cdot 79)$ & $3 \cdot 81$ & $6 \cdot 04$ & 9.90 \\
\hline$\alpha$-tocopherol (mg) & $7 \cdot 12$ & $(3.01)$ & $4 \cdot 22$ & $6 \cdot 49$ & $10 \cdot 78$ & $5 \cdot 56$ & $(2 \cdot 34)$ & $3 \cdot 24$ & $5 \cdot 14$ & $8 \cdot 29$ \\
\hline Vitamin C (mg) & $79 \cdot 4$ & $(36 \cdot 3)$ & $42 \cdot 0$ & $72 \cdot 4$ & 124.9 & $83 \cdot 7$ & $(42 \cdot 0)$ & $40 \cdot 5$ & $75 \cdot 1$ & 136.0 \\
\hline Energy $(\mathrm{MI})$ & $12 \cdot 52$ & $(3.91)$ & 8.08 & 12.03 & $17 \cdot 44$ & 8.98 & $(2 \cdot 87)$ & 5.69 & 8.59 & $12 \cdot 70$ \\
\hline
\end{tabular}

$\mathrm{REq}=$ retinol equivalents.

${ }^{*} \beta$-carotene equivalents.

Finnish foods. For liver vitamin A, values analysed in the late 1960 s were used. ${ }^{18}$ Figures for vitamin $\mathrm{C}$ were taken from Finnish food composition tables. ${ }^{19}$ Dietary vitamin A from preformed vitamin A and provitamin A carotenoids was calculated in retinol equivalents. ${ }^{20}$ Dietary carotenoids were estimated in $\beta$-carotene equivalents, consisting of $\beta$-carotene and half of the amounts of $\alpha$-carotene, $\gamma$-carotene, and cryptoxanthin. Vitamin E values, in $\alpha-$ tocopherol equivalents, were calculated from $\alpha$-tocopherol and other compounds with vitamin $\mathrm{E}$ activity using conversion factors suggested elsewhere ${ }^{21}$ Vitamin intakes were mainly based on the vitamin contents of uncooked foods. The dietary method and its reproducibility were described in detail in a previous study. ${ }^{22}$ Intraclass correlation coefficients for dietary $\beta$-carotene and vitamins $A, E$, and $C$, based on interviews repeated within four to eight months, ranged from 0.30 to 0.78 . The lowest figure was found for vitamin $\mathrm{A}$ and the highest for vitamin $\mathrm{E}$.

A premailed questionnaire checked by a study nurse at the examination provided information about smoking habits, occupation, and marital status. ${ }^{13}$ For smoking habits, subjects were classified into four groups: never smokers, ex-smokers, light smokers (smoking less than 15 cigarettes per day or only pipe or cigars), and heavy smokers (at least 15 cigarettes per day). Occupational categories were formed in the light of information supplied on the present or the latest former employment, according to a Nordic adaptation of the ILO classification. ${ }^{23}$ The subjects' weight and height were measured without shoes, in light indoor clothing. ${ }^{13}$ One or two kg were subtracted from the recorded weight depending on the amount of clothing, and the body mass index $\left(\mathrm{kg} / \mathrm{m}^{2}\right)$ was calculated.

Mean intakes of antioxidant vitamins and their percentage distributions were calculated. Associations between dietary antioxidant vitamin intakes and other personal characteristics were assessed by linear covariance analysis, ${ }^{24}$ using the pertinent nutrient as a dependant variable. Age, geographical region, occupational group, marital status, smoking habits, and body mass index were included in the model as independent variables one at a time. Age as a potential confounder was included in all analyses. Likewise in all analyses, secular confounding that might arise due to seasonal differences or time elapse was diminished by adjusting for geographical region. Analyses were made either adjusting or not adjusting for dietary energy, and finally multivariate analyses simultaneously including all non-dietary characteristics as independent variables were performed.

\section{Results}

Intakes and centile distributions of carotenoids, retinoids, vitamins $\mathrm{A}, \mathrm{E}$, and $\mathrm{C}$, and some other related nutrients and dietary energy in the study population are shown in table 1 . Total dietary vitamin A was mainly provided by preformed retinoids. Carotenoids accounted for 17 and $26 \%$ of the total dietary vitamin $\mathrm{A}$ in the average diet of men and women, respectively. Virtually all provitamin A activity of the diet was attributed to $\beta$-carotene intake. Estimated dietary vitamin $\mathrm{E}$ activity was mainly from $\alpha$-tocopherol intake. The distribution of vitamin intakes, and that of carotenoids in particular, was skewed to the right. Intakes of total and preformed dietary vitamin $\mathrm{A}$, vitamin $\mathrm{E}$, and dietary energy were higher in men, whereas those of carotenoids and vitamin $\mathrm{C}$ were higher in women.

Table 2 lists the percentage contribution of different food groups to the intake of the studied vitamins in the average diet of men and women. Vegetables provided the highest proportion of carotenoids, but total vitamin A was mainly supplied by animal foods, with a considerable proportion derived from liver. Several food sources, of both vegetable and animal origin, contributed to dietary vitamin E. Fruits and potatoes were the main food source of vitamin C.

Associations between personal characteristics and antioxidant vitamin intakes adjusted for age and geographical region are shown in table 3. Suggested associations were not notably changed by further adjustments for dietary energy or other personal characteristics, with a few exceptions quoted in the text. Results from all analyses are available from the author responsible for correspondence. A clear-cut decrease in dietary carotenoids was shown with increasing age (table 3). Married men were in a better position than men living alone. In women, marital status did not make a significant difference. Occupational group was an important determinant for dietary carotenoids, 
Table 2 The average percentage of dietary antioxidant vitamins provided by different foods

\begin{tabular}{|c|c|c|c|c|c|c|c|c|}
\hline \multirow[t]{3}{*}{ Food group } & \multicolumn{8}{|c|}{ Average amount of vitamin provided by the food group (\%) } \\
\hline & \multicolumn{2}{|c|}{ Carotenoids } & \multicolumn{2}{|c|}{ Vitamin $A(R E q)$} & \multicolumn{2}{|c|}{ Vitamin $E$} & \multicolumn{2}{|c|}{ Vitamin $C$} \\
\hline & Men & Women & Men & Women & Men & Women & Men & Women \\
\hline Cereals & & & & & 32 & 28 & & \\
\hline Potatoes & 1 & & & & 1 & 1 & 33 & 20 \\
\hline Vegetables & 70 & 84 & 12 & 22 & 4 & 6 & 18 & 21 \\
\hline Fruits, berries & 2 & 2 & & . & 6 & 10 & 36 & 50 \\
\hline Margarine, oils & & & 3 & 3 & 14 & 16 & & \\
\hline Butter & 14 & 7 & 24 & 18 & 10 & 9 & & \\
\hline Milk products & 10 & 5 & 24 & 18 & 10 & 9 & 12 & 8 \\
\hline Meat products* & 1 & 1 & 30 & 34 & 8 & 7 & 1 & 1 \\
\hline Fish & & & & & 7 & 5 & & \\
\hline Eiggs & & & 5 & 5 & 8 & 9 & & \\
\hline
\end{tabular}

$\mathrm{REq}=$ retinol equivalents

* Vitamin A mainly derived from liver.

white collar workers having the highest intake, and farmers the lowest intake. Differences between geographical regions in dietary carotenoids were significant. Men who were current smokers had lower intakes of carotenoids than ex-smokers or never smokers. The association between smoking and dietary carotenoids was not significant among women, but our results suggested that intakes were lowest for heavy smokers and highest for exsmokers. There were no significant differences in carotenoid intake according to body mass index.

Intakes of vitamin A were highest among young adults and lowest in the oldest age group (table 3). Unmarried men and women tended to have lower adjusted intakes of dietary vitamin A than those who were married, widowed, or divorced. Occupational group was closely associated with vitamin $A$ intake in a pattern similar to that shown for dietary carotenoids. There were significant differences in dietary vitamin A intakes between different regions, too. Smoking habits were not an important independent determinant for dietary vitamin A. There was a small decrease in dietary vitamin $A$ in the highest quartile of body mass index in women.

An inverse relationship between age and dietary vitamin $\mathrm{E}$ was evident (table 3 ). Differ-

Table 3 Adjusted* mean intake (mg/d) of carotenoids, vitamin $A$, vitamin $E$, and vitamin $C$ according to different demographic and health behaviour related characteristics in men and women

\begin{tabular}{|c|c|c|c|c|c|c|c|c|c|c|}
\hline \multirow[t]{2}{*}{ Variable } & \multicolumn{2}{|l|}{ No } & \multicolumn{2}{|c|}{ Carotenoids } & \multicolumn{2}{|c|}{ Vitamin $A(R E q)$} & \multicolumn{2}{|c|}{ Vitamin $E$} & \multicolumn{2}{|l|}{ Vitamin $C$} \\
\hline & Men & Women & Men & Women & Men & Women & Men & Women & Men & Women \\
\hline \multicolumn{11}{|l|}{ Age $(y) \dagger$} \\
\hline-19 & 597 & 561 & $2 \cdot 12$ & $2 \cdot 65$ & $1 \cdot 72$ & 1.53 & $9 \cdot 07$ & $6 \cdot 52$ & $88 \cdot 2$ & $84 \cdot 6$ \\
\hline $\begin{array}{l}20-29 \\
30-39\end{array}$ & 1117 & 1015 & 1.79 & $2 \cdot 75$ & $1 \cdot 78$ & $1 \cdot 70$ & 9.05 & $6 \cdot 90$ & $87 \cdot 7$ & $91 \cdot 7$ \\
\hline $\begin{array}{l}30-39 \\
40-49\end{array}$ & 1097 & 910 & $1 \cdot 78$ & $2 \cdot 52$ & $1 \cdot 79$ & $1 \cdot 70$ & $8 \cdot 87$ & 6.97 & $82 \cdot 2$ & $89 \cdot 2$ \\
\hline $\begin{array}{l}40-49 \\
50-50\end{array}$ & 1075 & 869 & $1 \cdot 80$ & $2 \cdot 40$ & $1 \cdot 72$ & 1.57 & $8 \cdot 58$ & $6 \cdot 70$ & $77 \cdot 7$ & $81 \cdot 2$ \\
\hline $50-59$ & 803 & 735 & 1.62 & $2 \cdot 27$ & 1.53 & 1.45 & $7 \cdot 78$ & $6 \cdot 20$ & $71 \cdot 0$ & $80 \cdot 0$ \\
\hline & 615 & 660 & 1.39 & $2 \cdot 05$ & 1.37 & $1 \cdot 37$ & $7 \cdot 15$ & $5 \cdot 73$ & $65 \cdot 1$ & $70 \cdot 5$ \\
\hline $\begin{array}{l}\text { p value for trend } \\
\text { Marital status: }\end{array}$ & \multicolumn{6}{|c|}{ Marital status: } & & & & $<0.001$ \\
\hline Unmarried & 1496 & 1313 & 1.65 & $2 \cdot 44$ & 1.54 & 1.50 & $8 \cdot 23$ & $6 \cdot 19$ & $74 \cdot 8$ & $82 \cdot 1$ \\
\hline Married & 3641 & 2876 & $1 \cdot 81$ & $2 \cdot 43$ & 1.73 & 1.58 & 8.61 & $6 \cdot 70$ & $81 \cdot 6$ & 83.9 \\
\hline Widowed, divorced & 164 & 556 & 1.50 & 2.66 & $1 \cdot 76$ & 1.67 & $8 \cdot 80$ & $6 \cdot 68$ & $74 \cdot 4$ & $86 \cdot 4$ \\
\hline \multicolumn{10}{|l|}{ Occupation: } & \\
\hline Agricultural & 1197 & 956 & 1.54 & $2 \cdot 08$ & 1.56 & 1.37 & $8 \cdot 72$ & $6 \cdot 68$ & $74 \cdot 1$ & $72 \cdot 6$ \\
\hline Industrial & 2276 & 613 & 1.65 & $2 \cdot 22$ & 1.68 & 1.56 & $8 \cdot 60$ & $6 \cdot 76$ & $78 \cdot 6$ & $81 \cdot 7$ \\
\hline Services & 1336 & 1694 & 1.95 & 2.53 & 1.71 & $1 \cdot 60$ & $8 \cdot 21$ & $6 \cdot 34$ & $81 \cdot 4$ & $85 \cdot 7$ \\
\hline White collar & 495 & 791 & $2 \cdot 26$ & $3 \cdot 02$ & $1 \cdot 88$ & $1 \cdot 84$ & $8 \cdot 39$ & $6 \cdot 69$ & $90 \cdot 8$ & $95 \cdot 9$ \\
\hline Housewives & & 696 & & $2 \cdot 39$ & & 1.49 & 0001 & $6 \cdot 62$ & & $82 \cdot 1$ \\
\hline \multicolumn{11}{|l|}{ Geographical region $\ddagger$} \\
\hline $\begin{array}{l}\text { Southwestern } \\
(1967,1969) \S\end{array}$ & 1053 & 1162 & $1 \cdot 78$ & $2 \cdot 40$ & $1 \cdot 70$ & $1 \cdot 62$ & $8 \cdot 06$ & $6 \cdot 50$ & $86 \cdot 1$ & $91 \cdot 4$ \\
\hline $\begin{array}{l}\text { Western } \\
(1968)\end{array}$ & 596 & 414 & 1.43 & $2 \cdot 12$ & $1 \cdot 46$ & $1 \cdot 33$ & $7 \cdot 25$ & $5 \cdot 84$ & $69 \cdot 5$ & $65 \cdot 9$ \\
\hline $\begin{array}{l}\text { Central } \\
\text { (1968) }\end{array}$ & 641 & 619 & $1 \cdot 73$ & $2 \cdot 50$ & 1.52 & $1 \cdot 47$ & $7 \cdot 66$ & $6 \cdot 13$ & $73 \cdot 7$ & $75 \cdot 4$ \\
\hline $\begin{array}{l}\text { Northern } \\
(1969,1970)\end{array}$ & 911 & 1046 & $1 \cdot 70$ & $2 \cdot 38$ & 1.84 & 1.63 & 8.99 & $6 \cdot 62$ & $77 \cdot 3$ & $82 \cdot 3$ \\
\hline $\begin{array}{l}\text { Southern } \\
\text { (1970) }\end{array}$ & 710 & 496 & 1.95 & $2 \cdot 66$ & $1 \cdot 76$ & $1 \cdot 66$ & $9 \cdot 24$ & $7 \cdot 38$ & $73 \cdot 7$ & $75 \cdot 7$ \\
\hline $\begin{array}{l}\text { Eastern } \\
(1971,1972)\end{array}$ & 1393 & 1013 & $1 \cdot 82$ & $2 \cdot 62$ & $1 \cdot 68$ & 1.57 & $9 \cdot 08$ & $6 \cdot 73$ & $85 \cdot 6$ & $92 \cdot 6$ \\
\hline \multicolumn{6}{|l|}{ Smoking status: } & $<0.001$ & $<0.001$ & $<0.001$ & $<0.001$ & $<0.001$ \\
\hline Never smoker & 1512 & 3645 & 1.83 & $2 \cdot 45$ & 1.65 & 1.55 & $8 \cdot 27$ & $6 \cdot 44$ & $80 \cdot 9$ & $82 \cdot 7$ \\
\hline Ex-smoker & 1103 & 246 & $1 \cdot 84$ & $2 \cdot 71$ & 1.69 & 1.70 & 8.52 & 6.98 & $80 \cdot 7$ & $93 \cdot 2$ \\
\hline Light smoker & 1382 & 761 & $1 \cdot 73$ & $2 \cdot 47$ & 1.66 & $1 \cdot 64$ & $8 \cdot 65$ & 6.91 & $78 \cdot 4$ & $85 \cdot 4$ \\
\hline Heavy smoker & 1306 & 94 & 1.63 & 1.92 & 1.72 & 1.50 & $8 \cdot 62$ & $7 \cdot 29$ & $77 \cdot 8$ & $83 \cdot 1$ \\
\hline \multirow{2}{*}{\multicolumn{8}{|c|}{ Body mass index $\left(\mathrm{kg} / \mathrm{m}^{2}\right)^{* *}$}} & $<0.001$ & 0.04 & 0.01 \\
\hline & 1302 & 1164 & 1.75 & $2 \cdot 42$ & 1.61 & & & & & \\
\hline Second & 1408 & 1272 & 1.73 & 2.57 & 1.72 & $\begin{array}{l}1.63 \\
-63\end{array}$ & 8.60 & $\begin{array}{l}0.11 \\
6.66\end{array}$ & $\begin{array}{l}77 \cdot 3 \\
79 \cdot 5\end{array}$ & $\begin{array}{l}85 \cdot 4 \\
85 \cdot 3\end{array}$ \\
\hline Third & 1310 & 1182 & 1.75 & 2.49 & 1.69 & 1.61 & $8 \cdot 64$ & 6.50 & $80 \cdot 6$ & $82 \cdot 1$ \\
\hline Fourth & 1282 & 1128 & 1.79 & $2 \cdot 33$ & 1.68 & 1.44 & 8.56 & $6 \cdot 37$ & $80 \cdot 2$ & 81.8 \\
\hline $\mathrm{p}$ value for trend & & & 0.47 & $0 \cdot 30$ & $0 \cdot 13$ & $<0.01$ & 0.01 & $<0.01$ & 0.02 & 0.03 \\
\hline
\end{tabular}

Adjusted for age and geographical region; $\nmid$ not adjusted for age; $\neq$ not adjusted for geographical region; $\$$ the year of the baseline study; ** quartile of body mass index. 
ences in marital status implied a lower adjusted intake of vitamin $\mathrm{E}$ among the unmarried. Occupational group was significantly associated with dietary vitamin $E$; the pattern of the effect, however, was dependent on energy adjustment. Total vitamin $\mathrm{E}$ intakes were highest in farmers and lowest in white collar workers. For energy adjusted values, the opposite was true: white collar workers had the highest values and farmers the lowest values (data not shown). Results for geographical regions suggested higher vitamin $\mathrm{E}$ intakes in those regions studied more recently. Current smoking was positively associated with total dietary vitamin E, but energy adjustment changed the results of men so that the lowest values were found in heavy smokers and the highest in ex-smokers (data not shown). Body mass index and dietary vitamin $\mathrm{E}$ tended to be positively associated in men, but an inverse association was suggested for women.

A reduction with age was also evident for dietary vitamin C (table 3 ). Marital status did not significantly determine the intake of vitamin $\mathrm{C}$ among women, but married men had higher intakes of vitamin $\mathrm{C}$ than other men. There was a clear increase in vitamin $\mathrm{C}$ intake through occupational groups from farmers to white collar workers, with housewives coming in between. Dietary vitamin C intake levels were highest in the southwestern and eastern regions. Heavy smokers tended to have the lowest amount of vitamin $\mathrm{C}$ in their diet. Among women, the highest vitamin $\mathrm{C}$ intake was demonstrated in ex-smokers. The minor associations suggested between body mass index and dietary vitamin $C$ varied depending on adjustments for other variables (data not shown).

\section{Discussion}

In our study intakes of antioxidant vitamins were found to be associated with several other personal characteristics, the most important being age, occupational group, and smoking habits. It seemed that intakes of vitamin $\mathrm{C}$ and carotenoids were affected more than those of vitamin A or vitamin $\mathrm{E}$. In most aspects dietary carotenoids and vitamin $C$ behave rather similarly, suggesting that their intakes were associated with a similar dietary pattern, although, in general, they were not derived from the same food source. The associations shown between sociodemographic characteristics and smoking and dietary antioxidant vitamin intakes were largely independent of other personal characteristics. The importance of dietary energy adjustment was evident, however, especially for dietary vitamin $\mathrm{E}$.

Greater intakes of dietary carotenoids and vitamin $\mathrm{C}$ among women than among men were evident in all classifications used. Smaller sex differences in dietary carotenoids and vitamin $\mathrm{C}$ can be found in other populations, ${ }^{8}$ and some studies have shown greater absolute intakes of these vitamins in men than in women..$^{625}$ When expressed $/ \mathrm{kg}$ body weight, dietary vitamin $\mathrm{C}$ was reported to be higher in women than men, especially in older age groups. ${ }^{6}$ In accordance with previous find- ings, ${ }^{8926}$ vitamin $\mathrm{E}$ was found to be higher in the diet of men. When related to dietary energy all antioxidant vitamins have been reported to be greater in the diet of women. ${ }^{27}$

The inverse association shown between age and the intake of antioxidant nutrients in this study suggests that an ageing body may be less well equipped to resist oxidative tissue damage, which may increase as body ages. Decreased serum concentrations of $\alpha$-tocopherol ${ }^{28}$ and $\beta$ carotene $^{29}$ in older groups were reported previously in subjects drawn from the present study population. The relationship between age and antioxidant vitamin intake may vary in different populations, however, and it seems to depend on the expression of nutrient intake data. Although previous results suggesting lower intakes of vitamin $\mathrm{E}$ with increasing age $^{926}$ are consistent with our findings, some studies have shown similar or even slightly higher absolute dietary intakes of vitamin A and $C$ in older groups ${ }^{6925}$ When expressed in terms of $/ \mathrm{kg}$ body weight, an inverse association between dietary vitamin $\mathrm{C}$ and age was found in men, but no significant effect of age was found in women. ${ }^{6}$ Nutrient densities for vitamins A, C, and E were reported to be stable or raised with age in one previous study. ${ }^{30}$ Our result, suggesting the beneficial effect of marriage on dietary carotenoids in men, agrees with previous findings on serum $\beta$-carotene and marital status. ${ }^{29}$ Differences in vitamin intakes between geographical regions apparently reflected the suggested geographical diversity in dietary patterns. ${ }^{14}$ However, differences ascribed to region may be partly due to secular changes in food consumption in Finland during the years of the baseline study. ${ }^{31}$

The importance of occupational group and other measures related to social standing as determinants of dietary intake has been suggested in previous studies from different countries. ${ }^{57832-34}$ Most of these, however, deal with the intake of foods and nutrients other than antioxidant vitamins. Dietary habits seem to be less healthy in manual than non-manual workers who are usually associated with a higher standard of education and social esteem..$^{583233}$ As in previous studies that reported intakes of dietary antioxidant vitamins, ${ }^{5833}$ our results suggested that people in generally nonmanual occupations, for example white collar workers and those employed in services, were in a better position than farmers and industrial workers. In the population studied, occupation was one of the most important non-dietary determinants for antioxidant vitamins, especially for dietary carotenoids and vitamin C. At variance with the findings of some previous studies, ${ }^{512}$ our results even suggested that the effect of occupation on dietary antioxidant vitamins was greater than that of smoking habits.

The poorer nutritional status of smokers in respect of antioxidant vitamins has been suggested in previous studies. ${ }^{35}$ Although serum carotene and vitamin $C$ concentrations, seem to be more directly affected by current smoking, ${ }^{3637}$ the nutritional status of smokers may be further compromised by inadequacies of diet. In line with previous studies, $511122736-38$ 
carotenoid and vitamin $\mathrm{C}$ contents were found to be lower in the diet of smokers, especially in men. In contrast to dietary carotene, smoking was not an important determinant of dietary vitamin $A$ in this study, obviously because of the impact of retinol on total dietary vitamin A. According to most previous studies, dietary retinol is not significantly affected by smoking, ${ }^{12}$ or may even be higher in current smokers. ${ }^{1127}$

The relationship between smoking and vitamin $\mathrm{E}$ seems to be enigmatic. In the present study, current smoking and dietary vitamin $\mathbf{E}$ tended to be positively associated, a finding that was partly explained by differences in dietary energy. Previous studies have reported lower intakes of vitamin $E$ in current smokers than in non-smokers. ${ }^{122739}$ Determinations of serum $\alpha$-tocopherol do not suggest any outstanding association between smoking and vitamin $\mathbf{E}$ status. ${ }^{35}$ However, some previous studies have reported significantly ${ }^{40}$ or non-significantly ${ }^{41}$ lower serum $\alpha$-tocopherol values in smokers than in non-smokers.

Our findings that ex-smokers have higher antioxidant vitamin intakes than current smokers, and that women's diets have improved more than those of men, are in line with previous studies suggesting that ex-smokers have a healthier diet than current smokers, ${ }^{5} 273942$ and that dietary changes appear sooner in women than in men. ${ }^{27}$ The somewhat different effects of smoking on the dietary habits of men and women, also suggested in the present study, may be associated with differences in social status and health related behaviours between sexes. ${ }^{112733}$

To our knowledge, the relationship between body mass index and dietary antioxidant vitamins has not been reported in other populations. In general, the relationship between body mass index and dietary data is complex, and findings concerning adiposity and dietary intakes have been conflicting. ${ }^{53}$ In our study, body mass index and dietary antioxidant vitamins were only weakly related. The slight inverse association between body mass index and some dietary antioxidant vitamins in women shown in this study may refer to lower physical activity or attempts to lose weight among subjects with a greater body mass index, or may reflect potential under-reporting of dietary intakes among obese subjects. ${ }^{44}$

In our study dietary antioxidant vitamin intakes were calculated from diets surveyed by the dietary history interview method. Although absolute figures for nutrient intakes may not be obtained by these history interviews, it has been suggested that this method is suitable for nutritional epidemiological research, where rating of subjects according to their relative dietary intakes is important. ${ }^{15}$ The availability of new Finnish food composition values provided by an advanced technique of analysing dietary carotenoids, retinoids, tocopherols, and tocotrienols, ${ }^{16}{ }^{17}$ enabled us to calculate intakes of carotenoids, and vitamins $\mathrm{A}$ and $\mathrm{E}$ more precisely than before. Positive correlations were previously demonstrated between $\beta$-carotene in the diet and in serum, ${ }^{29}$ and between dietary vitamin $E$ and serum tocopherol values. ${ }^{41}$
In conclusion, dietary antioxidant vitamin intakes were found to be closely associated with age, occupational group, and smoking habits. These characteristics are also risk determinants for chronic diseases such as cancer and coronary heart disease. In general, dietary intakes of carotenoids and vitamin $C$ were found to be affected more strongly and in a very similar pattern. In contrast, the associations of vitamin $E$ and other personal variables were less consistent and depended especially on energy adjustment. Despite potential cultural differences between populations, our results support previous findings suggesting that current smokers and manual workers are nutritionally in a poorer position than non-smokers and nonmanual workers. Accordingly, the impacts of dietary antioxidant vitamins and non-dietary risk factors on the occurence of chronic disease may be compounded by each other, and these inter-relationships should be considered in nutritional epidemiological studies concerning chronic diseases with a multifactorial background.

Byers T, Perry G. Dietary carotenes, vitamin C, and vitamin Byers T, Perry G. Dietary carotenes, vitamin C, and vitamin E as protective antioxidar

2 Gey KF. On the antioxidant hypothesis with regard to arteriosclerosis. Bibl Nutr Dieta 1986;37:53-91.

3 Gaziano JM, Manson JE, Buring JE, Hennekens $\mathrm{CH}$ Dietary antioxidants and cardiovascular disease. Ann NY Acad Sci 1992;669:249-58

4 Cronin FJ, Krebs-Smith SM, Wyse BW, Light L. Characterizing food usage by demographic variables. $\mathcal{f} \mathrm{Am}$ Diet Assoc 1982;81:661-73.

5 Fehily AM, Phillips KM, Yarnell JWG. Diet, smoking, social class, and body mass index in the Caerphilly Heart Disease Study. Am F Clin Nutr 1984;40:827-33.

6 Block G, Sorenson A. Vitamin C intake and dietary sources by demographic characteristics. Nutr Cancer 1987;10:5365.

7 Fulton M, Thomson M, Elton RA, Brown S, Wood DA Oliver MF. Cigarette smoking, social class and nutrient intake: relevance to coronary heart disease. Eur $\Im$ Clin intake: relevance to cor $1988 ; 42: 797-803$.

8 Bolton-Smith C, Smith WCS, Woodward M, TunstallPedoe $H$. Nutrient intakes of different social-class groups: results from the Scottish heart health study (SHHS). $B$ f Nutr 1991;65:321-35.

9 Block G, Subar AF. Estimates of nutrient intake from a food frequency questionnaire: The 1987 national health interview survey. I Am Diet Assoc 1992;92:969-77.

10 Hulshof KFAM, Wedel M, Löwik MRH, et al. Clustering of dietary variables and other lifestyle factors (Dutch Nutritional Surveillance System). $\mathcal{J}$ Epidemol Community Health 1992;46:417-24.

11 La Vecchia C, Negri E, Franceschi S, Parazzini F, Decarli A. Differences in dietary intake with smoking, alcohol, and education. Nutr Cancer 1992;17:297-304.

12 Thompson RL, Margetts BM, Wood DA, Jackson AA Cigarette smoking and food and nutrient intakes in relation to coronary heart disease. Nutr Res Rev 1992;5:131-52.

13 Knekt P. Serum alpha-tocopherol and the risk of cancer. Helsinki: Social Insurance Institution, Finland, Series ML: sinki: Social

14 Koskinen EH. The food consumption and nutrient intake of Finns in 1967 to 1969 . (In Finnish, with an English sum-
intion mary.) Helsinki: Social Insurance Institution, Finland, Series ML:6, 1975 .

15 Block G, Hartman AM. Dietary assessment methods. In: Moon TE, Micozzi MS, eds. Nutrition and cancer prevention. Investigating the role of micronutrients. New York: Marcel Decker, 1989: 159-80.

16 Piironen V. Tocopherols and tocotrienols in foods and in the average Finnish diet. (In Finnish with an English summary.) Helsinki: University of Helsinki, Department of Food Chemistry and Food Technology, EKT series 726, 1986.

17 Heinonen M Camtenoids and retinoids in Finnish foods and the average diet. Helsinki: University of Helsinki, Department of Food Chemistry and Food Technology, EKT series $811,1990$.

18 Antila P, Varesmaa E, Niinivaara FP. Über die Jahreszeitlichen Variationen im Nährstoffgehalt der Leber. $Z$ Landwirtschafis-wissenschaftichen Gesellschaft Finnland 1968;40:19-25.

19 Rastas M, Seppänen R, Knuts R-L, Karvetti R-L, Varo P, eds. Nutrient composition of foods. Helsinki: Social Insurance Institution, Finland, 1989. 
20 National Research Council. Recommended dietary allowances. 10th ed. Washington, DC: National Academy Press, 1989.

21 McLaughlin PJ, Weihrauch JL. Vitamin E content of foods. f Am Diet Assoc 1979;75:647-65.

22 Järvinen R, Seppänen R, Knekt P. Short-term and longterm reproducibility of dietary history interview data. In term reproducibility of diet

23 Brockington F. World health. Appendix VIII. The in ternational standard classification of occupations, 2nd edn London: Churchill, 1967:331-9.

24 Cohen J, Cohen P. Applied multiple regression/correlation analysis for the behavioral sciences. New York: John Wiley \& Sons, 1975.

25 Pao EM, Mickle SJ, Burk MC. One-day and 3-day nutrien intakes by individuals - Nationwide Food Consumption Survey findings, spring 1977. F Am Diet Assoc 1985;85: 313-24.

26 Murphy SP, Subar AF, Block G. Vitamin E intakes and sources in the United States. Am f Clin Nutr 1990;52 361-7.

27 Bolton-Smith C, Woodward M, Brown CA, TunstallPedoe $H$. Nutrient intake by duration of ex-smoking in the Scottish heart health study. BrF Nutr 1993;69:315-32.

28 Knekt P, Seppänen R, Aaran R-K. Determinants of serum alpha-tocopherol in Finnish adults. Prev Med 1988;17: alpha-tocop.

29 Järvinen R, Knekt P, Seppänen R, Heinonen M, Aaran R-K Dietary determinants of serum $\beta$-carotene and serum retinol. Eur f Clin Nutr 1993;47:31-41.

30 Bolton-Smith C, Smith WCS, Woodward M, TunstallPedoe $\mathrm{H}$. Age trends in nutrient intakes for non-manual and manual occupational groups: the Scottish heart health study (abstract). Proc Nutr Soc 1990;49:63A.

31 Seppänen R. Nutrition in Finland. (In Finnish.) Duodecim 1982;98:1666-73.

32 Aro S, Räsänen L, Telama R. Social class and changes in health-related habits in Finland in 1973-1983. Scand 7 Soc Med 1986;14:39-47.

33 Braddon FEM, Wadsworth MEJ, Davies JMC Cripps HA. Social and regional differences in food and alcohol consumption and their measurement in a national birth consumption and their measurement in a national birth

34 Hulshof KFAM, Löwik MRH, Kok FJ, et al. Diet and other life-style factors in high and low socio-economic groups (Dutch nutrition surveillance system). Eur f Clin Nutr 1991;45:441-50.

35 Preston AM. Cigarette smoking - nutritional implications. Prog Food Nutr Sci 1991;15:183-217.

36 Stryker WS, Kaplan LA, Stein EA, Stampfer MJ, Sober A, Willett WC. The relationship of diet, cigarette smoking and alcohol consumption to plasma beta-carotene and alpha-tocopherol levels. Am $\mathcal{F}$ Epidemiol 1988;127:283-96.

37 Schectman G. Estimating ascorbic acid requirements for cigarette smokers. Ann NY Acad Sci 1993;686:335-45.

38 Subar AF, Harlan LC, Mattson ME. Food and nutrient intake differences between smokers and non-smokers in the US. Am 7 Public Health 1990;80:1323-9.

39 Cade JE, Margetts BM. Relationship between diet and smoking - Is the diet of smokers different? $\mathcal{f}$ Epidemiol Community Health 1991;45:270-2.

40 Herbeth B, Chavance M, Musse N, Vernhes G. Determinants of plasma retinol, beta-carotene, and alphaterminants of plasma retinol, beta-carotene,

41 Knekt P. Vitamin $\mathrm{E}$ and smoking and the risk of lung Knekt P. Vitamin $\mathrm{E}$ and smoking and the

42 Kato I, Tominaga S, Suzuki T. Characteristics of past smokers. Int $\mathcal{F}$ Epidemiol 1989;18:345-54.

43 Baecke JAH, van Staveren WA, Burema J. Food consumption, habitual physical activity, and body fatness in young Dutch adults. Am $\mathcal{F}$ Clin Nutr 1983;37:278-86.

44 Prentice AM, Black AE, Coward WA, et al. High level of energy expenditure in obese women. BMF 1986;292: $983-7$.

\section{Cancer patient survival by socioeconomic status in seven countries: a review for six common cancer sites}

Carola T M Schrijvers, Johan P Mackenbach

\begin{abstract}
Study objective - To study the size and consistency of socioeconomic differences in cancer patient survival as reported in published studies.

Methods - A systematic review was coriducted. Several criteria were developed to select the study material, which resulted in 14 reports on socioeconomic differences in survival for cancers of the colon, rectum, lung, prostate, breast, and cervix. These present results on patients from the United States, Japan, Australia, United Kingdom, Sweden, Finland, and Germany. The results are summarised in a relative risk of dying or survival ratio for
\end{abstract}

the lowest socioeconomic status group compared with the highest.

Results - For cancers of the colon, rectum, breast, and cervix, patients from higher socioeconomic status groups had a better survival. For lung cancer and cancer of the prostate, results were unclear.

Conclusion-Socioeconomic differences in cancer survival are generally small and their contribution to socioeconomic differences in cancer mortality is probably small too. These findings have implications for the type of health policy measures which should be taken to reduce socioeconomic differences in cancer mortality.

Corrigendum: An article was published in the October issue entitled "Cancer patient survival by socioeconomic status in The Netherlands: a review for six common cancer sites" ( $F$ Epidemiol Community Health 1994; 48: 441-6). This title was incorrect and misleading. The corrected title is printed above, together with the abstract. 